\title{
Research on the Mechanism of Social Mobilization in Major Public Health Emergencies-Taking the COVID- 19 Epidemic as an Example
}

\author{
Xibo Sun ${ }^{1}$, Jiajia Liang ${ }^{1, *}$ and Ke Wang ${ }^{1}$ \\ ${ }^{1}$ College of Economics and Management, Harbin Engineering University, Harbin, Heilongjiang Province 150001 \\ *Corresponding author. Email: liangjiajia0927@163.com
}

\begin{abstract}
To solve major public health emergencies, it is inseparable from a government with a strong organization and mobilization ability, and even more so with grassroots forces. Social mobilization is an important means of emergency management. So how does the social mobilization mechanism play a role in this process? This article adopts the method of case analysis and grounded theory. Based on the case data of the new crown epidemic, a three-level coding analysis was carried out and a theoretical model was established. In the context of the deteriorating crisis, the identity of the mobilized, the particularity of personality and values, the organizational capabilities of government agencies, the mobilization capabilities of emergency culture, the mobilization capabilities of new media, and the state's emergency management capabilities constitute the social mobilization mechanism. Combining the characteristics of different mechanisms, the paper finally puts forward suggestions to improve the social mobilization mechanism. This article fills in the theoretical gap of using qualitative research methods to study social mobilization.
\end{abstract}

Keywords: major public health emergencies; social mobilization mechanism; grounded theory; COVID-19

\section{INTRODUCTION}

As our country moves from an industrial society to an information society, public crises have increasingly shown obvious uncertainty, high complexity, prominent systemicity, and strong leaps and bounds. In the face of a complex and changeable crisis management environment, the country must adhere to the network crisis management model of multiple co-governance, and give full play to social forces. When a major public health emergency encounters a modern society where members of the society move rapidly, the crisis will be difficult to resolve if social mobilization is not adopted. The new crown pneumonia epidemic that broke out and spread in early 2020 is a major public health emergency, and the number of confirmed cases nationwide has soared during the crisis. More than 30 provinces across the country have launched a first-level emergency response, and the State Council has launched a joint prevention and control work mechanism. From the perspective of the international antiepidemic situation, countries have basically adopted social mobilization to control the Epidemic. The anti-epidemic results of China, South Korea, Singapore and other countries have demonstrated the important role of social mobilization in the management of major public emergencies. From the perspective of major public crisis management, this article focuses on the social mobilization mechanism under major public health emergencies, combined with the case of the new crown pneumonia epidemic, and uses grounded theoretical research methods to clarify the hard and soft mechanisms of social mobilization. Exploring ways to improve the social mobilization mechanism will help to promote the modernization of national crisis management capabilities.

\section{RELATED RESEARCH ON SOCIAL MOBILIZATION}

\subsection{Review of Foreign Research}

The academic research on social mobilization has its roots in the 1930s. The American scholar Kaldoic [1] first explained the meaning of social mobilization and believed that social mobilization was accompanied by the alternation of the old and new social models. Foreign scholars are paying more and more attention to the power of social mobilization. They believe that spontaneous social mobilization is an important factor in solving public crises in pandemic management[2]. In recent years, Western scholars have analyzed the important factors that affect social mobilization from different angles, and believe that social ties and social media affect the effects of social mobilization. The research topics of foreign scholars mainly focus on the dynamics of social mobilization, mobilization channels, differences in mobilization under different institutional backgrounds, and research on better social mobilization methods[3-7]. There are few studies on social mobilization in the context of major public health emergencies. 


\subsection{Domestic Research Review}

Chinese scholars' research on social mobilization has undergone a process of transition from historical events to actual events. Some scholars link historical events with social mobilization, and study social mobilization in special historical periods based on history. Liu Yibo[8] analyzed the period of the Central Soviet Area. Some other scholars study social mobilization from a realistic perspective, mainly using the Internet and public opinion, grassroots governance, and emergencies as the starting points. First, starting with the Internet and public opinion, scholars studied the strategies and limits of social mobilization from the perspective of the Internet, the mechanism and path of social mobilization on the Internet, and the internal relationship between emotional choice and social mobilization in the context of Internet public opinion [9-11]. Secondly, with grassroots governance as an entry point, current research focuses on three aspects: the technical support of social mobilization, the functions and boundaries of social mobilization, and the social mobilization mechanism and governance effects in rural construction. In recent years, with the increase of nontraditional security threats, the number of studies that take emergencies as the starting point has gradually increased. Some scholars have studied and analyzed the superiority of social mobilization in the Epidemic, and affirmed the superiority of social mobilization in the context of the Epidemic [12-13].

\section{THE GROUNDED THEORETICAL PROCESS OF SOCIAL MOBILIZATION MECHANISM IN MAJOR PUBLIC HEALTH EMERGENCIES PREPARED}

This article uses grounded-theory qualitative research methods to study the social mobilization mechanism in major public health emergencies. Conduct three-level coding analysis and theoretical saturation test on interview data and news report data, and gradually conceptualize and categorize the original data. Finally, the core category is obtained, and a theoretical model of the social mobilization mechanism in major public health emergencies is constructed.

\subsection{Data Collection}

The original data is the basis of grounded theoretical research. The data in this article consists of interview data and official news reports. Thirty-two interviewees were selected for in-depth interview test. Considering the wide range of mobilization during the Epidemic, there are differences in the identities of the mobilized objects. The interviewees involved medical staff, college students, community volunteers, social workers, grassroots community cadres, community workers, grassroots public security police, ordinary people, highway traffic workers, Vulcan Mountain builders, grassroots party member volunteers, and corporate employees who participated in the conversion of medical supplies. Authoritative news reports during the epidemic period were selected as supplementary materials.

\subsection{Theoretical Sampling}

In the process of analyzing authoritative news reports and interview data, it is found that the motives of social mobilization objects to participate in social mobilization are different due to differences in identity and external environment. Therefore, this paper randomly selects $3 / 4$ of the original data, and decodes them according to the identity of the mobilized object, and constructs a theoretical model. And use the remaining quarter of the original data to verify whether the theory is saturated, so as to completely analyze the social mobilization mechanism under the background of major public health emergencies.

\subsection{Open Coding}

First of all, the initial conceptualization of the original interview data and news report data is carried out to obtain 74 initial concepts. After integrating and summarizing the initial concepts, constantly comparing the relationship between each initial concept and each category, and summarizing concepts with the same or similar meanings into the same category, thirty-six categories were finally obtained. As shown in Table 1.

Table 1. Examples of open coding

\begin{tabular}{|l|l|l|l|}
\hline \multirow{2}{*}{ Interviewee } & \multicolumn{1}{|c|}{ Open coding process } \\
\cline { 2 - 4 } A05 & $\begin{array}{l}\text { Interviews and observations } \\
\text { I am an old party member in our } \\
\text { community. If the situation is special, we } \\
\text { old party members are willing to be the first } \\
\text { to join. }\end{array}$ & $\begin{array}{l}\text { Consciousness of } \\
\text { veteran party members } \\
\text { in the community }\end{array}$ & $\begin{array}{l}\text { Party members' own } \\
\text { literacy }\end{array}$ \\
\hline A07 & $\begin{array}{l}\text { Because the family members are all party } \\
\text { members, affected by the environment, } \\
\text { when there is a crisis, they want to dedicate } \\
\text { themselves. }\end{array}$ & $\begin{array}{l}\text { In the environment of a } \\
\text { party member's family }\end{array}$ & $\begin{array}{l}\text { The influence of the } \\
\text { family environment of } \\
\text { party members }\end{array}$ \\
\hline A18 & In such times of crisis, as a party member & Need to join as a party & Responsibilities of party \\
\hline
\end{tabular}




\begin{tabular}{|l|l|l|l|}
\hline \multirow{2}{*}{ Interviewee } & \multicolumn{1}{c|}{ Open coding process } & \multicolumn{1}{c|}{ Initial concept } & \multicolumn{1}{c|}{ Categorization } \\
\cline { 2 - 4 } & $\begin{array}{l}\text { and cadre, of course, one has to keep the } \\
\text { needs of the masses in mind and fulfill the } \\
\text { promise that I am a party member and I go } \\
\text { first. }\end{array}$ & member and cadre & cadres \\
\hline A01 & $\begin{array}{l}\text { I think as a doctor, this is what we should } \\
\text { do. }\end{array}$ & $\begin{array}{l}\text { What the doctor should } \\
\text { do }\end{array}$ & $\begin{array}{l}\text { Doctor's professional } \\
\text { mission }\end{array}$ \\
\hline A02 & $\begin{array}{l}\text { It is the mission of every medical worker to } \\
\text { save the dead and heal the wounded. }\end{array}$ & $\begin{array}{l}\text { The mission of a } \\
\text { medical worker }\end{array}$ & $\begin{array}{l}\text { Occupational Specificity } \\
\text { of Medical Workers }\end{array}$ \\
\hline$\ldots$ & $\ldots$ & $\ldots$ & $\ldots$ \\
\hline
\end{tabular}

Note: Due to space constraints, this article only selects some tables to describe the research process.

Source: interviews and authoritative news reports.

\subsection{Spindle Decoding}

Open coding has many categories of the dynamic mechanism of social mobilization, but these categories are relatively scattered and some have similar meanings. By analyzing detailed category information, and carrying out spindle decoding according to the interrelationship and internal logic of each category, fourteen main categories are obtained. The main categories include individual party member status, professional mission, deterioration of the crisis environment, personal values, industry experience, job responsibilities, media appeal ability, spiritual role model guidance, organizational arrangements, national emergency mobilization capabilities, family environment influence, the character of social responsibility, financial support and individual personality. As shown in Table 2.

Table 2. Main category formed by spindle decoding

\begin{tabular}{|c|c|c|}
\hline \multirow{2}{*}{$\begin{array}{l}\text { The main category of } \\
\text { social mobilization } \\
\text { mechanism in major } \\
\text { public health } \\
\text { emergencies }\end{array}$} & \multicolumn{2}{|c|}{ The process of secondary coding } \\
\hline & Corresponding category & Relationship connotation \\
\hline $\begin{array}{l}\text { Party membership of } \\
\text { the mobilization object }\end{array}$ & $\begin{array}{l}\text { 1.Party members' own literacy } \\
\text { 2.The influence of the family } \\
\text { environment of party members } \\
\text { 3.Responsibilities of party cadres }\end{array}$ & $\begin{array}{l}\text { Reflect the influence of party member status on } \\
\text { behavior }\end{array}$ \\
\hline Career mission & $\begin{array}{l}\text { 1.Doctor's professional mission } \\
\text { 2.Occupational Specificity of Medical } \\
\text { Workers }\end{array}$ & $\begin{array}{l}\text { Reflecting the possibility that occupation determines } \\
\text { certain behaviors }\end{array}$ \\
\hline $\begin{array}{l}\text { The deterioration of the } \\
\text { crisis environment }\end{array}$ & $\begin{array}{l}\text { 1.Outpatient volume surged } \\
\text { 2.Increased demand for personnel } \\
\text { 3.Increased workload }\end{array}$ & $\begin{array}{l}\text { Environmental changes will affect individual } \\
\text { behavior }\end{array}$ \\
\hline Personal values & $\begin{array}{l}\text { 1.The spirit of selfless dedication } \\
\text { 2.Helping others } \\
\text { 3.Serve the people }\end{array}$ & Values influence individual behavior \\
\hline Industry experience & $\begin{array}{l}\text { 1.Crisis management experience } \\
\text { 2.Rich industry experience }\end{array}$ & $\begin{array}{l}\text { Industry experience and behavioral inertia affect } \\
\text { individual behavior }\end{array}$ \\
\hline Job responsibilities & $\begin{array}{l}\text { 1.Responsibility } \\
\text { 2.Job responsibilities of grassroots } \\
\text { cadres }\end{array}$ & $\begin{array}{l}\text { The work environment affects the individual' } s \\
\text { degree of responsibility }\end{array}$ \\
\hline Media appeal & $\begin{array}{l}\text { 1.Network information dissemination } \\
\text { 2.Media reports } \\
\text { 3.Propaganda of mainstream media } \\
\text { news }\end{array}$ & $\begin{array}{l}\text { The external environment affects individual } \\
\text { behavior }\end{array}$ \\
\hline $\begin{array}{l}\text { Guidance by a spiritual } \\
\text { role model }\end{array}$ & $\begin{array}{l}\text { 1.The spread of touching stories } \\
\text { 2.Lead by example }\end{array}$ & Group behavior affects individual behavior \\
\hline $\begin{array}{l}\text { Organizational } \\
\text { arrangements }\end{array}$ & $\begin{array}{l}\text { 1.The call of the community } \\
\text { 2.Community worker requirements }\end{array}$ & $\begin{array}{l}\text { The identity of the individual restricts the behavior } \\
\text { of the individual }\end{array}$ \\
\hline
\end{tabular}




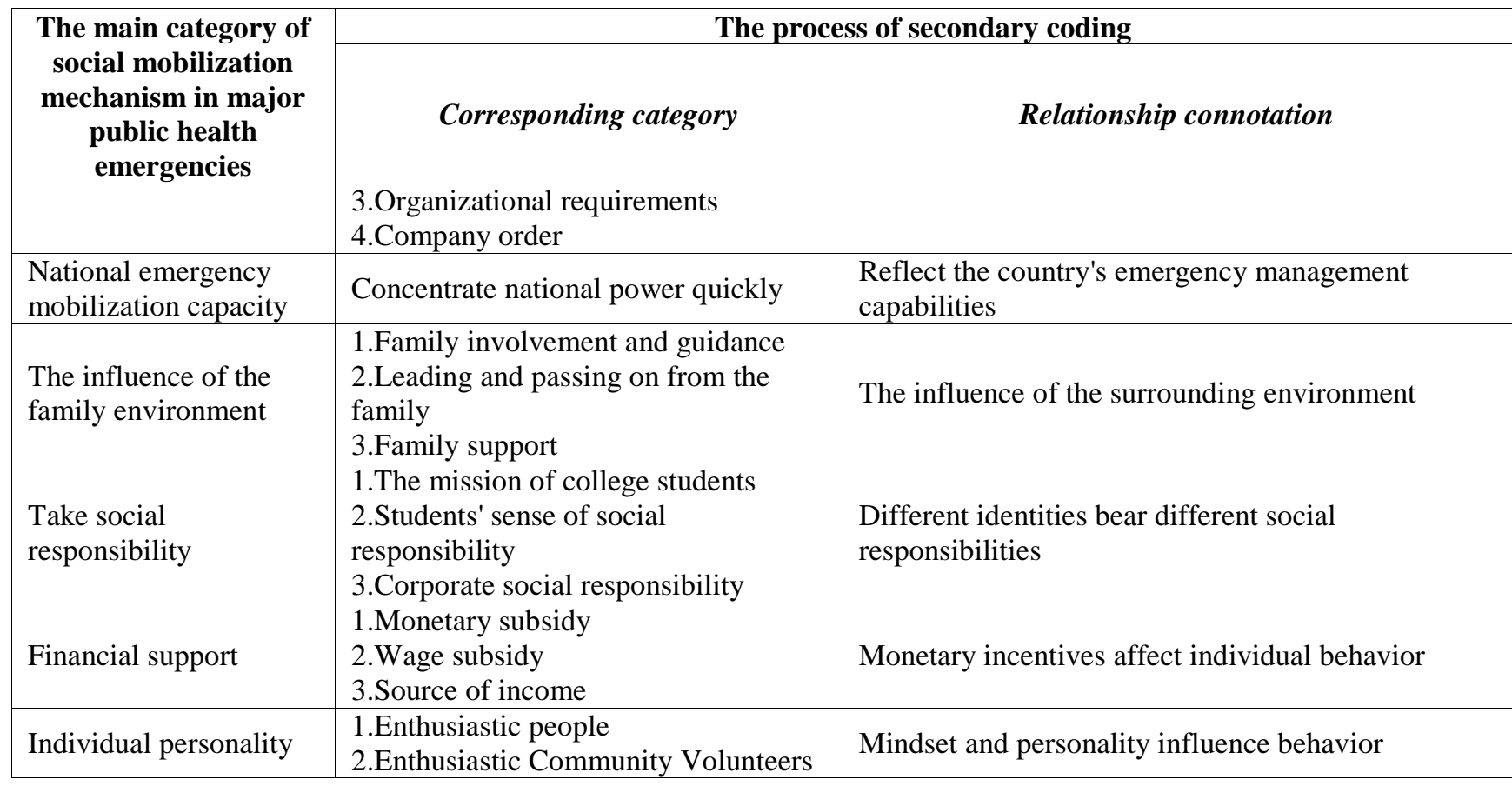

\subsection{Core Decoding}

Continue to analyze the results obtained by optimizing the spindle decoding, and finally summarize the core category. Taking "Social Mobilization Mechanism in Major Public Health Emergencies" as the core theme, an in-depth analysis of the 14 main categories formed by the main axis decoding is carried out. It is concluded that in the context of the worsening crisis, the core categories include the particularity of the mobilizer's identity, personality and values, the organizational capabilities of government agencies, the mobilization capabilities of emergency culture, the mobilization capabilities of new media, and the country's emergency management capabilities. As shown in Figure 1.

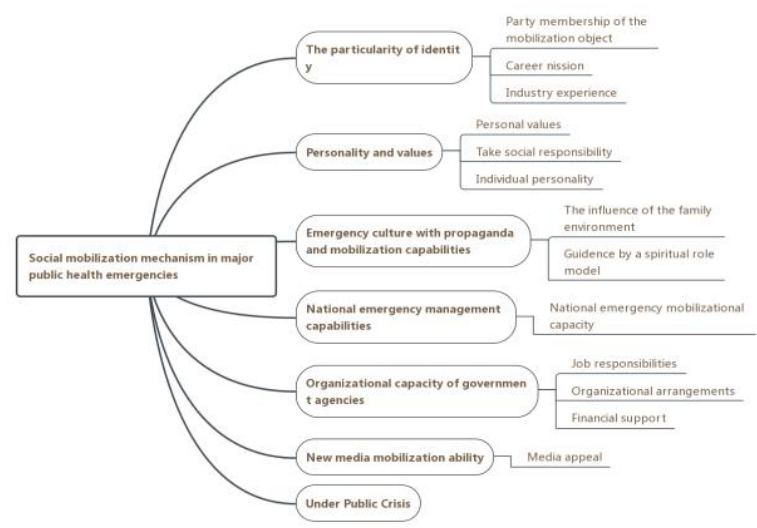

Figure 1. Theoretical model of social mobilization mechanism in major public health emergencies.

\subsection{Saturation Test of Theoretical Model}

Analyze, integrate and encode the remaining $1 / 4$ of the original data according to the previous coding steps to verify whether the theory is saturated. In this process, no new important categories and relationships emerged. Therefore, the conceptual model established in this research is theoretically saturated.

\section{EFFECTIVE OPERATING MECHANISM OF SOCIAL MOBILIZATION}

Mechanism refers to the structural relationship and operation mode among various elements. When a crisis occurs, the social mobilization mechanism usually responds quickly and rescues in a timely manner, providing the government with auxiliary rescue forces. The success of social mobilization during the period of new coronary pneumonia is inseparable from the role of hard and soft mechanisms.

\subsection{The Hard Mechanism of Social Mobilization}

\subsubsection{Use institutional advantages to show the country's emergency management capabilities}

Using the advantages of my country's socialist system, in the event of a major natural disaster or public crisis, it is usually possible to quickly concentrate the nation's power, that is, to have the "capability of concentrating power to do 
big things." Many serious public crises often appear suddenly during a certain period of time. At this time, all kinds of gossip in the society are overflowing, and the people are uneasy. Only when the country quickly stepped up to explain the true situation of the crisis and carried out efficient social mobilization can it provide a behavioral framework for media mobilization and cultural mobilization. In this context, whether the government can quickly integrate resources and mobilize the people to maintain social stability and maintain the smooth operation of the state apparatus reflects the strength of emergency mobilization capabilities. The advantages of my country's system, the correct perception of the crisis and the rapid decision-making behavior of the central government are the deep-seated factors for the success of social mobilization, and both are the hard mechanism of social mobilization.

\subsubsection{The organizational capabilities of government agencies and an emergency management system with clearly defined powers and responsibilities}

From the founding of New China to 2003, my country's emergency management research was in its infancy. The emergency management mechanism is an emergency management deliberative coordination mechanism led by categorized management and led by temporary agencies, mainly for single-hazard risk management. The "Emergency Regulations for Public Emergencies" promulgated during the SARS period brought public health emergency treatment into the track of the rule of law. The "Emergency Response Law" promulgated by my country in 2007 is a milestone in emergency law. It has improved my country's emergency management system, stipulated the ownership of leadership, and highlighted the principle of territoriality. When a major public health incident occurs, the Ministry of Health shall take the lead in handling and be responsible. My country has formed a comprehensive and coordinated emergency management mechanism, which has overcome some of the problems that have occurred in previous political mobilization.

\subsection{The Soft Mechanism of Social Mobilization}

\subsubsection{New media mobilization ability}

With the rapid development of the Internet and news media, the media mobilization mechanism has become the mainstay of the soft social mobilization mechanism, playing an indelible role in the face of major public health emergencies. Media mobilization refers to "the process of using mass media resources to influence the values and actions of the general public". The media mainly include official media controlled by government personnel and non-official media managed by civil organizations and personnel. In the event of a major public crisis, the public is prone to feel uneasy, anxious and negative. The media mobilization mechanism must play its own role to stabilize the public's mentality. On the one hand, the government should pass on the real situation and information of the crisis to the public through official media. On the other hand, media mobilization mechanisms usually play three important roles when major public health emergencies occur. First, clarify anti-epidemic methods. Second, through the media to promote touching stories in the fight against the Epidemic, mobilize more volunteers to participate, and obtain human and material support. Third, gather emotional power and spread the national spirit.

\subsubsection{Propaganda and mobilization capacity of emergency culture}

Emergency culture usually plays a role of guidance, cohesion, motivation and regulation. Emergency cultural propaganda is to enable people to hold correct emergency concepts and values in the process of preventing and responding to crises, and to improve their self-protection skills in the face of public crises. In the process of building an emergency culture system, the government should play a leading role and assume the responsibility of building an emergency culture. The media, various social organizations and communities must play a role in dissemination and implementation. In the event of a major public crisis, the emergency culture mobilization mechanism, as a soft mechanism, can usually play a good supplementary role. Emergency cultural mobilization should not only be carried out when disasters occur, but also emergency cultural propaganda and emergency cultural mobilization should be carried out during the daily disaster prevention phase and the post-disaster recovery phase.

\subsubsection{The particularity of individual identity and Cultivation of personality and values}

From the individual microscopic point of view, in the external environment of the outbreak of public crises, it is often necessary to mobilize a group of special groups. Due to their different social identities and professional attributes, they play a different role from ordinary people in the process of resolving the crisis. When party members are a special group in the country for emergency mobilization, they insist on taking the people as the center and daring to take up the challenge in the face of crises. The medical staff must escort the lives of the people. These individuals with special identities have led to the overall atmosphere of social mobilization.

Differences in individual personality and values will affect the effect of social mobilization. Environmental factors affect a person's personality, the cultural background of growth and the behavior of surrounding family members 
and friends will affect the individual's personality. Responsible and easy-going individuals are generally easier to mobilize. Values represent basic beliefs and affect the attitudes and behaviors of micro-subjects. Individual personality characteristics and values determine the difficulty of mobilization.

\section{CONCLUSION}

This paper studies the social mobilization mechanism in major public health emergencies and establishes a theoretical model. It is concluded that the national emergency management capabilities, the organizational capabilities of government agencies, the mobilization capabilities of emergency culture, the mobilization capabilities of new media, the particularity of the mobilizer's identity, and the personality and values all affect the effectiveness of social mobilization.

To optimize the social mobilization mechanism, we can proceed from the following three aspects. First, we must strengthen the legal system and improve the emergency management organization system. Second, the government must establish a unified and efficient material allocation system. The completeness of the material allocation system is the material basis for the success of social mobilization. Third, all types of media must serve as a good microphone for social mobilization. Finally, in the face of major public health emergencies and other major public crises, crises can be quickly resolved.

\section{ACKNOWLEDGMENT}

Thanks to the 32 interviewees who participated in the interview. Thanks to Social Science Foundation of Heilongjiang Province of China(20JYB043) and the Chinese Fundamental Research Funds for the Central Universities (HEU: 3072020CFT0903) for funding.

\section{REFERENCES}

[1] Karl Deutsch, Social Mobilization and Political Development. Foreign Politics. 1987.

[2] Wan KM, Ho LKK, Wong NWM and Chiu A, Fighting COVID-19 in Hong Kong: The effects of community and social mobilization. World Development, vol. 134, October 2020. DOI: 10. 1016/J. WORLDDEV. 2020. 105055

[3] Stefaan Walgrave, and Pauline Ketelaars, The recruitment functions of social ties: Weak and strong tie mobilization for 84 demonstrations in eight countries. International Journal of Comparative Sociology, vol. 60, pp. 301-323. October 2019. DOI: 10.

$1177 / 0020715219888942$
[4] Brantly, From Cyberspace to Independence Square: Understanding the Impact of Social Media on Physical Protest Mobilization During Ukraine's Euromaidan Revolution. Journal of Information Technology \& Politics, vol. 16, pp. 360-378. October 2019. DOI: 10. 1080/19331681. 2019. 1657047

[5] Rogers T, Goldstein NJ and Fox CR. Social Mobilization. Annual Review of Psychology, vol. 69, PP. 357-381. January 2018. DOI: 10. 1146/ANNUREV-PSYCH-122414-033718

[6] Boulianne Shelley, Koc-Michalska Karolina, and Bimber Bruce, Mobilizing media: comparing TV and social media effects on protest mobilization. Information Communication \& Society, vol. 23, pp. 642-664. April 2020. DOI: 10. 1080/1369118X. 2020. 1713847

[7] Schapper Andrea, Unrau Christine, and Killoh Sarah, Social mobilization against large hydroelectric dams: A comparison of Ethiopia, Brazil, and Panama. Sustainable Development, vol. 28, pp. 413-423. September 2019. DOI: 10. 1002/sd. 1995

[8] Liu Y. B. The People's Livelihood Construction and Social Mobilization in the Central Soviet Area. Nankai Journal (Philosophy and Social Sciences Edition), vol. 3, pp. 31-39. May 2017. (In Chinese)

[9] Liu X. L. Strategies and Limits of the Mobilization of the Network Society from the Perspective of Micropolitics-An Empirical Study Based on the Environmental Struggle QQ Group in City Z. Journal of Yunnan Administration Institute, vol. 5, pp. 101-111. September 2019. (In Chinese)

[10] Xu M. and Li Z. G. Mobilization Mechanism and Path Selection of Network Society. Chinese Administration, vol. 10, pp. 51-56. October 2016. (In Chinese)

[11] Du Z. F. and Guo Z. Y. The Internal Logic of Emotional Choice and Social Mobilization in Weibo Public Opinion- Based on the Case Analysis of "Shandong Yuhuan Case". Modern Communication (Journal of Communication University of China), vol. 8, pp. 20-24+29. August 2019. (In Chinese)

[12] Gao Z. W. and Duan W. J. The CCP's Social Mobilization for Schistosomiasis Prevention and Control in the Early New China. Journal of Xiamen University (Philosophy and Social Sciences Edition), vol. 2, pp. 152-161. March 2020. (In Chinese)

[13] Zhao M. S. How does social mobilization realize the "epidemic" without hesitation. People's Forum, vol. Z2, pp. 24-26. May 2020. (In Chinese) 